\title{
GLYCEROKINASE AND ITS POSSIBLE ROLE IN GLYCEROL METABOLISM OF BULL SPERMATOZOA*
}

\author{
H. MOHRI AND J. MASAKI \\ Biological Institute, College of General Education, \\ University of Tokyo, Tokyo, and \\ National Institute of Animal Industry, Chiba, Japan
}

(Received 21st April 1966)

\begin{abstract}
Summary. Glycerokinase occurs in ejaculated bull spermatozoa. Characteristics of the spermatozoan glycerokinase are quite similar to those of rat liver glycerokinase, except that the enzyme is firmly bound to the midpieces (mitochondria). The addition of L-glycerol-3-phosphate, as well as of free glycerol, to the washed bull spermatozoa causes both an increase in oxygen uptake and an accumulation of lactic acid. Since bull spermatozoa possess neither $\mathrm{NAD}^{+}$- nor $\mathrm{NADP}^{+}$-linked glycerol dehydrogenase, L-glycerol-3-phosphate would be formed by the action of glycerokinase as the initial step of glycerol metabolism in bull spermatozoa, followed by its oxidation to dihydroxyacetonephosphate by the mitochondrial dehydrogenase, via the glycolytic pathway. Among other animals, fowl and ram spermatozoa show high specific activity of glycerokinase. The enzyme activity is low in boar spermatozoa, and is not detectable in rabbit, human, rainbow trout, starfish and seaurchin spermatozoa.
\end{abstract}

\section{INTRODUCTION}

It is now well established that glycerol exerts beneficial effects on spermatozoa during long-term storage at $-79^{\circ} \mathrm{C}$ or below. Since the observation by White, Blackshaw \& Emmens (1954) that glycerol markedly increases the oxygen uptake of washed ram and bull spermatozoa, evidence has been accumulated to indicate that these spermatozoa metabolize glycerol under aerobic conditions (O'Dell, Flipse \& Almquist, 1956; Mann \& White, 1957; White, 1957), although this does not seem to be responsible for the protecting action of glycerol in deep freezing. From the results that washed ram spermatozoa oxidize dihydroxyacetone as readily as glycerol, and dephosphorylate $\alpha$ - and $\beta$ phosphoglycerol which also stimulate the oxygen uptake, it has been suggested that the initial dehydrogenation of glycerol to dihydroxyacetone is involved in glycerol metabolism (Mann \& White, 1957). On the other hand, studies on the isolated midpieces, consisting of mitochondrial complex, from bull spermatozoa revealed that L-glycerol-3-phosphate ( $\alpha$-phosphoglycerol) is oxidized at the highest rate among several substrates tested, while no oxidation of free

* This paper is dedicated to Professor Juro Ishida on the occasion of his sixtieth birthday. 
glycerol takes place in the isolated midpieces (Mohri, Mohri \& Ernster, 1965). Furthermore, the presence of glycerokinase, an enzyme catalysing the formation of L-glycerol-3-phosphate from glycerol and adenosinetriphosphate (ATP), was demonstrated in bull spermatozoa. These results raised the possibility that glycerol is phosphorylated as the first step of its utilization and then oxidized by mitochondrial enzyme to dihydroxyacetonephosphate, which in turn enters the glycolytic machinery.

The present investigation was undertaken to examine the properties and the localization of bull sperm glycerokinase. The distribution of spermatozoan glycerokinase among several species was also examined. The results will be discussed in relation to glycerol metabolism in bull and other spermatozoa.

\section{MATERIALS AND METHODS}

Bull semen was collected with an artificial vagina. Spermatozoa were separated from seminal plasma by centrifugation, and washed once with $\mathrm{Ca}^{2+}$-free Ringer solution for spermatozoa (Mann, 1946). The washed spermatozoa were diluted with $0.25 \mathrm{~m}$ sucrose up to the original volume and sonicated in cold for $2 \mathrm{~min}$ in a Kubota KMS-100 sonic disintegrator at a frequency of 10 kilocycles. The sonicate thus obtained was then fractionated into head, midpiece, tail and soluble fractions as described by Mohri et al. (1965). To determine the enzyme activity of whole semen, either the semen was directly sonicated, or the separated seminal plasma and the sperm sonicate were combined in the original proportion. The same result was obtained in both cases. In some cases, semen and spermatozoa were homogenized, but incomplete disruption of the spermatozoa resulted.

Ram, boar and rabbit semen were also obtained by using artificial vaginae. In the case of boar, a sperm-rich fraction of semen was used. Cock semen was obtained by the massaging method. Human semen was supplied by the Department of Obstetrics and Gynecology, School of Medicine, Keio University, and rainbow trout semen by the Irikawa Hatchery. Sea-urchin semen was obtained by injecting a few drops of $0.5 \mathrm{M} \mathrm{KCl}$ into the body cavity of male animals. Starfish semen was shed following injection of radial nerve extract (Kanatani, 1964). Semen or spermatozoa of these materials were also treated as described above.

Glycerokinase activity was assayed according to the method of Bublitz \& Kennedy (1954), the L-glycerol-3-phosphate formed being measured enzymatically by following the optical change at $340 \mathrm{~m} \mu$ of $\mathrm{NAD}^{+}$(Hohorst, 1963a). In some cases, glycerokinase activity was directly observed by recording the change at $340 \mathrm{~m} \mu$ in the following medium: $0.2 \mathrm{M}$ hydrazine $-0.5 \mathrm{~m}$ glycine buffer $\mathrm{pH} 9.5 ; 10^{-3} \mathrm{M} \mathrm{MgCl}_{2} ; 6 \times 10^{-3} \mathrm{M} \mathrm{ATP}_{2} 2 \times 10^{-2} \mathrm{M}$ cysteine; $2.5 \times 10^{-2}$ м KF $; 10^{-3}$ м NAD ${ }^{+} ; 10^{-2}$ м glycerol; $10 \mu$ l Baranowski enzyme (crystalline $\mathrm{NAD}^{+}$-linked L-glycerol-3-phosphate dehydrogenase from rabbit muscle) and enzyme sample, in a total volume of $3 \mathrm{ml}$. The amount of enzyme catalysing the formation of $0.1 \mu$ moles of L-glycerol-3-phosphate/hr is expressed as one unit.

$\mathrm{NAD}^{+}$- and $\mathrm{NADP}^{+}$-linked glycerol dehydrogenase activity were measured 
according to the method of Burton (1955), by following the increase in optical density at $340 \mathrm{~m} \mu$ at an alkaline $\mathrm{pH}$, using glycerol as substrate. The reverse reactions, i.e. the oxidation of NADH or NADPH coupled with the reduction of dihydroxyacetone or glyceraldehyde to glycerol, were also examined as described by Chino (1960). Phosphatase assay was made in a system consisting of 0.025 м Tris- $\mathrm{HCl}$ buffer, $\mathrm{pH} 7.4 ; 10^{-3} \mathrm{M} \mathrm{MgCl}_{2} ; 2.5 \times 10^{-2} \mathrm{M} \mathrm{KF} ; 3 \times 10^{-3}$ M DL-glycerol-3-phosphate and enzyme preparation, in a total volume of $1 \mathrm{ml}$, at $37^{\circ} \mathrm{C}$. Liberated inorganic phosphate was determined according to Fiske \& Subbarow (1925).

Lactate (Hohorst, 1963b), dihydroxyacetonephosphate (Bücher \& Hohorst, 1963) and glycerol (Wieland, 1963) were determined by enzymatic methods. Glycerol was also determined by the method of Ryley (1955), as modified by White (1959).

The oxygen uptake was measured by the direct Warburg method, at $37^{\circ} \mathrm{C}$. Once-washed spermatozoa were suspended in the $\mathrm{Ca}^{2+}$-free Ringer solution with care to avoid injuring the sperm cells.

TABLE 1

GLYCEROKINASE ACTIVITY OF SEMEN, SEMINAL PLASMA AND

SPERMATOZOA

\begin{tabular}{|c|c|c|c|c|}
\hline & \multirow{2}{*}{$\begin{array}{l}\text { No. of } \\
\text { exps. }\end{array}$} & \multicolumn{3}{|c|}{ Activity (unit/mg protein) } \\
\hline & & Semen & Seminal plasma & Spermatozoa \\
\hline $\begin{array}{l}\text { Bull } \\
\text { Homogenate } \\
\text { Sonicate } \\
\text { Ram }\end{array}$ & $\begin{array}{l}4 \\
6\end{array}$ & $\begin{array}{l}0.04 \pm 0.01 \\
0.03 \pm 0.02\end{array}$ & $\begin{array}{l}0.00 \\
0.00\end{array}$ & $\begin{array}{l}0.46 \pm 0.08 \\
0.81 \pm 0.20\end{array}$ \\
\hline $\begin{array}{l}\text { Homogenate } \\
\text { Sonicate }\end{array}$ & $\begin{array}{l}1 \\
5\end{array}$ & $\begin{array}{l}0.07 \\
0.17 \pm 0.04\end{array}$ & $\begin{array}{l}0.00 \\
0 \cdot 00\end{array}$ & $\begin{array}{l}0.32 \\
0.95 \pm 0.17\end{array}$ \\
\hline
\end{tabular}

One unit corresponds to $0.1 \mu$ moles of L-glycerol-3-phosphate formed $/ \mathrm{hr}$.

The total nitrogen content was estimated by direct Nesslerization after the combustion of samples, and multiplied by 6.25 in order to calculate the amount of protein. Sperm counts were made with a haemocytometer.

All chemicals and enzymes used were commercially available products. De-ionized water was used in the preparation of all solutions.

\section{RESULTS}

Glycerokinase activity in bull and ram semen

As shown in Table 1, homogenates or sonicates of both bull and ram spermatozoa washed free of seminal plasma exhibited relatively high glycerokinase activities, while no activities were detectable in the seminal plasma of either material. Although the whole semen also showed some glycerokinase activity, such activity was very low as compared with that of the washed spermatozoa, even if the presence of the seminal plasma in the whole semen is taken into consideration. This could be interpreted as indicating that the potent seminal 
phosphatase immediately hydrolysed the L-glycerol-3-phosphate formed by the action of the spermatozoan glycerokinase, resulting in an apparently low glycerokinase activity in homogenates or sonicates of whole semen. In fact, the seminal plasma showed sufficiently high phosphatase activity toward DLglycerol-3-phosphate when glycerokinase assays were performed under similar conditions (Table 2).

TABLE 2

PHOSPHATASE AGTIVITY OF SEMINAL PLASMA

\begin{tabular}{l|c}
\hline Animals & $\begin{array}{c}\text { Activity } \\
\text { (unit/mg protein) }\end{array}$ \\
\hline Bull & $1 \cdot 33$ \\
Ram & 2.43 \\
\hline
\end{tabular}

One unit corresponds to $0 \cdot 1 \mu$ moles of inorganic phosphate liberated from DLglycerol-3-phosphate/hr.

Glycerokinase activities obtained with the sonicates were much higher than those of the homogenates. This might be due to the fact that sonication brought about more complete disruption of sperm cells, permitting the substrate to enter more readily. This interpretation is also supported by the fact that the enzyme activity increased somewhat after repeated freezing and thawing of the enzyme preparations.

\section{Localization of bull sperm glycerokinase}

Glycerokinase is known as one of the soluble enzymes, although the phosphorylation of glycerol catalysed by this enzyme is considered as an essential step in the synthesis of neutral fats or phospholipids, which takes place in mitochondria. The data presented in Table 3 indicate that the spermatozoan

TABLE 3

DISTRIBUTION OF GLYGEROKINASE AGTIVITY IN SPERM FRAGTIONS

\begin{tabular}{c|c|c|c|c|c}
\hline & \multicolumn{5}{|c}{ Activity (unit/mg protein) } \\
\cline { 2 - 6 } Bull & Sonicate & Head & Mid-piece & Tail & Soluble \\
\hline I & 1.01 & 0.15 & 4.12 & 1.47 & - \\
II & 0.87 & 0.22 & 4.26 & 1.87 & - \\
III & 0.95 & 0.10 & 4.08 & 0.68 & 0.08 \\
& & & & & \\
\hline
\end{tabular}

glycerokinase is highly concentrated in the isolated midpiece fraction. The head fraction possesses practically no enzyme activity and the activity of the tail fraction is much lower than that of the midpiece fraction. Little activity remained in the soluble fraction obtained after centrifugation of the tail fraction, i.e. the supernatant after removal of heads and midpieces, at $100,000 \mathrm{~g}$ for $60 \mathrm{~min}$. 
Furthermore, attempts to dissolve the glycerokinase from the midpiece fraction, including extraction with acetate buffer at $\mathrm{pH} 5.2$ (which is effective in obtaining glycerokinase from rat liver or other sources in a soluble form), prolonged sonication, digitonin treatment and n-butanol extraction, have so far been unsuccessful, although a preparation with very weak activity was obtained after extraction of acetone-dried powder of the sonicated midpieces. These results seem to indicate that the spermatozoan glycerokinase is rather firmly bound to the midpieces, possibly to the mitochondria.

\section{Properties of bull sperm glycerokinase}

Since it was found difficult to dissolve the spermatozoan glycerokinase, some properties of this enzyme were examined with the isolated mid-piece fraction. Text-fig. 1(a) and (b) indicate that the amount of L-glycerol-3-phosphate
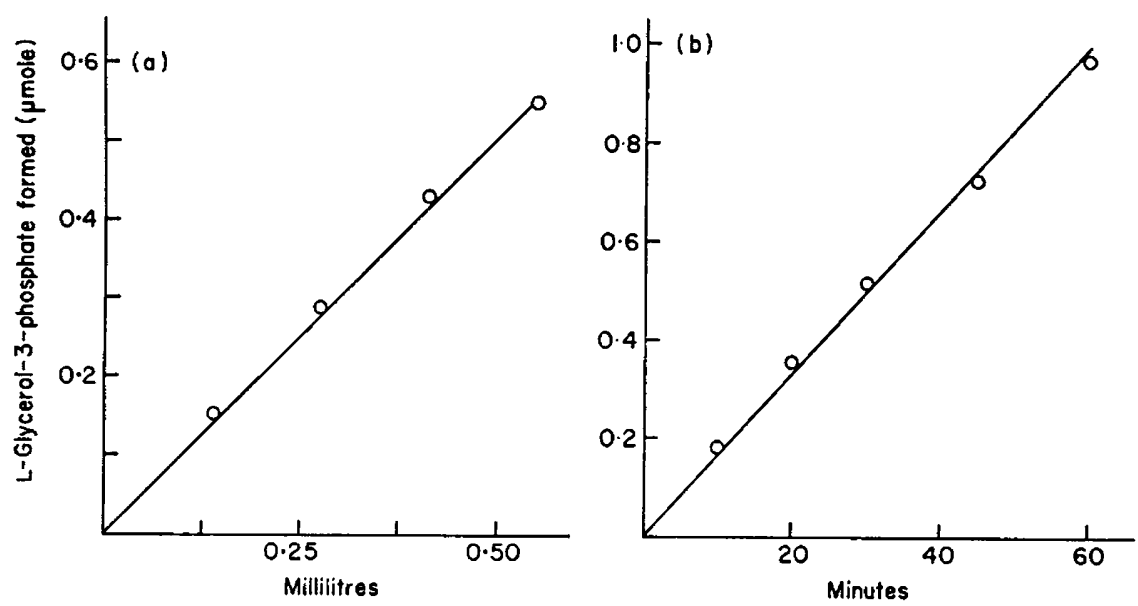

TEXT-FIG. 1. (a) Effect of enzyme concentration on the reaction velocity of glycerokinase from bull spermatozoa. (b) Effect of incubation time on the spermatozoan glycerokinase.

formed is proportional, in the ranges shown, to both enzyme concentration and time. As can be seen from Text-fig. 2, the maximal rate of the reaction was obtained at about $\mathrm{pH} \mathrm{10.0.} \mathrm{The} \mathrm{pH}$-activity curve is similar to that of rat liver glycerokinase (Bublitz \& Kennedy, 1954). Text-fig. 3 is a LineweaverBurk plot of the reciprocals of rate of enzyme action versus the reciprocals of substrate concentration. The Michaelis constant obtained from this figure was about $4 \times 10^{-4} \mathrm{M}$. At higher concentrations of substrate, the reaction rate was depressed.

Both glycerol and dihydroxyacetone have been reported to be substrates for rat liver glycerokinase, the latter being phosphorylated more rapidly by the enzyme action (Bublitz \& Kennedy, 1954). As indicated in Table 4, the spermatozoan glycerokinase also phosphorylated these two substrates. The rate, however, was higher with glycerol than with dihydroxyacetone under the present experimental conditions. 


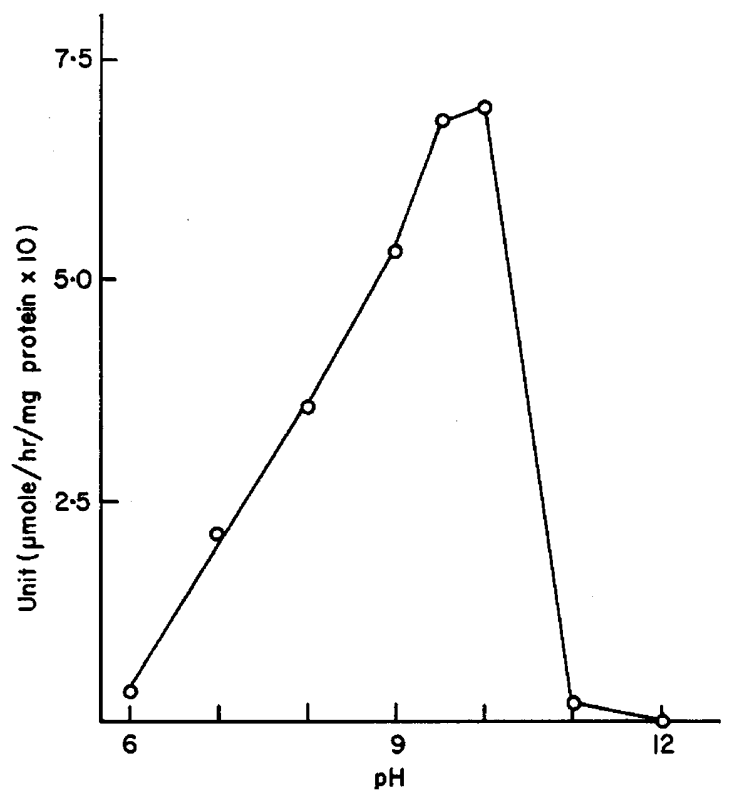

TEXT-FIG. 2. $\mathrm{pH}$-activity curve of glycerokinase from bull spermatozoa. $0.025 \mathrm{M}$ histidine buffer, adjusted with $\mathrm{HCl}$ or $\mathrm{NaOH}$ to desired $\mathrm{pH}$.

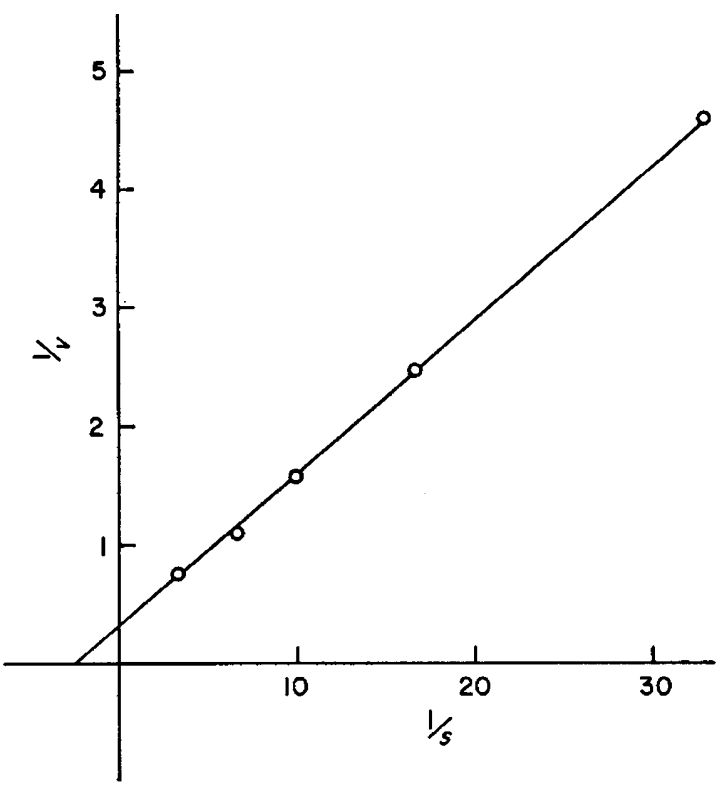

TexT-Fig. 3. Lineweaver-Burk plot of glycerokinase from bull spermatozoa. Ordinate: reciprocal of rate of phosphorylation of glycerol $(1 / v=1 / 10 \mathrm{unit}=1 / \mathrm{m} \mu \mathrm{mole} / \mathrm{hr} / \mathrm{mg}$ protein): abscissa: reciprocal of substrate concentration $(1 / s=1 / \mathrm{mm})$. 
TABLE 4

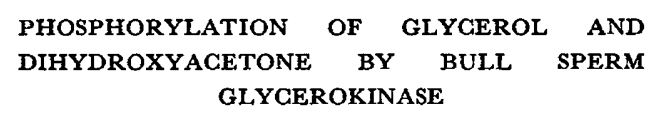

\begin{tabular}{c|c|c}
\hline \multirow{2}{*}{$\begin{array}{c}\text { Exp. } \\
\text { no. }\end{array}$} & \multicolumn{2}{|c}{ Activity (unit/mg protein) } \\
\cline { 2 - 3 } & Glycerol & Dihydroxyacetone \\
\hline 1 & $6 \cdot 11$ & 3.31 \\
2 & 5.73 & 3.36 \\
\hline
\end{tabular}

One unit corresponds to $0 \cdot 1 \mu$ moles of $\mathrm{L}-$ glycerol-3phosphate or dihydroxyacetonephosphate formed/hr.

\section{Distribution of spermatozoan glycerokinase}

Among several animal species examined, cock spermatozoa exhibited the highest activity of glycerokinase (about three times as high as that of bull spermatozoa) followed by ram and bull spermatozoa (Table 5). Boar spermatozoa showed a relatively low glycerokinase activity, while no appreciable activity was detectable in human, rabbit, rainbow trout, two species of seaurchin or starfish spermatozoa. The enzyme activity of seminal plasma was negligible in all of these species.

TABLE 5

DISTRIBUTION OF SPERMATOZOAN GLYGEROKINASE

\begin{tabular}{|c|c|c|c|c|}
\hline \multirow{2}{*}{ Animals } & \multirow{2}{*}{$\begin{array}{l}\text { No. of } \\
\text { exps. }\end{array}$} & \multicolumn{3}{|c|}{ Activity (unit/mg protein) } \\
\hline & & Semen & Seminal plasma & Spermatozoa \\
\hline $\begin{array}{l}\text { Bull } \\
\text { Ram } \\
\text { Boar } \\
\text { Rabbit } \\
\text { Human } \\
\text { Cock } \\
\text { Rainbow trout } \\
\text { Sea-urchin } \\
\text { Pseudocentrotus depressus } \\
\text { Hemicentrotus pulcherrimus } \\
\text { Starfish (Asterias amurensis) }\end{array}$ & $\begin{array}{l}6 \\
5 \\
2 \\
2 \\
2 \\
2 \\
1 \\
1 \\
1 \\
1\end{array}$ & $\begin{array}{l}0.03 \pm 0.02 \\
0.17 \pm 0.04 \\
= \\
- \\
0.00 \\
- \\
- \\
0.00 \\
0.00 \\
0.00\end{array}$ & $\begin{array}{l}0.00 \\
0.00 \\
0 \cdot 09 \pm 0.06 \\
0.03 \pm 0.01 \\
0 \cdot 00 \\
0.02 \pm 0.02 \\
0.02 \\
\quad- \\
\quad- \\
\quad-\end{array}$ & $\begin{array}{l}0.81 \pm 0.20 \\
0.95 \pm 0.17 \\
0.25 \pm 0.08 \\
0.03 \pm 0.01 \\
0.00 \\
2.44 \pm 0.42 \\
0.01\end{array}$ \\
\hline
\end{tabular}

Such differences in glycerokinase activity of spermatozoa from species to species seem to be correlated with the difference in their pattern of glycerol metabolism, as will be discussed later.

\section{Glycerol dehydrogenase}

Two pathways at least of glycerol metabolism are known as follows:

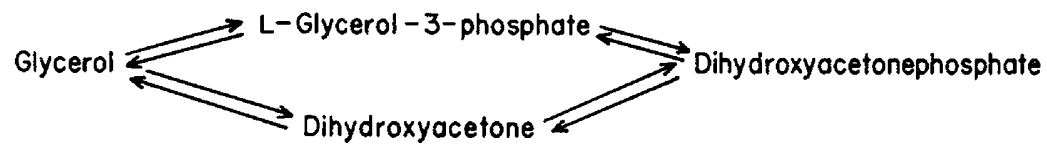


In determining which pathway is operating in the spermatozoa under investigation, it is desirable to test for the presence or absence of glycerol dehydrogenase. Two types of glycerol dehydrogenase have been reported, namely $\mathrm{NAD}^{+}$-linked (Burton, 1955) and NADP ${ }^{+}$-linked glycerol dehydrogenase (Faulkner, 1958). By the action of the former, glycerol would be converted to dihydroxyacetone, provided that a high concentration of glycerol is added or the product is continuously removed; the latter catalyses the interconversion between glycerol and dihydroxyacetone or glyceraldehyde.

Text-fig. 4 indicates that bull spermatozoa show no appreciable activity of either type of glycerol dehydrogenase as compared with the high activity of glycerokinase in the same sample, when glycerol was used as substrate.

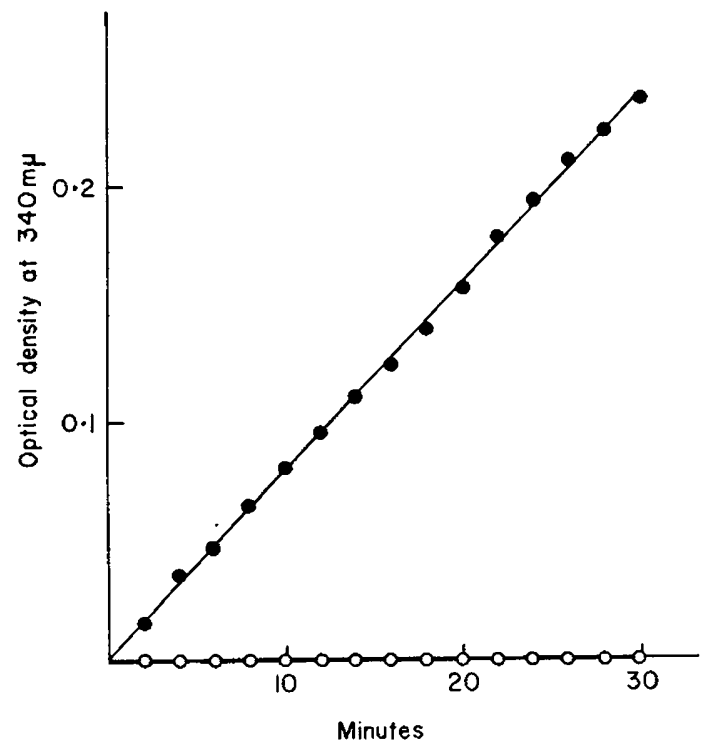

Text-Fig. 4. Glycerokinase and glycerol dehydrogenase of bull spermatozoa. Glycerokinase; $0.2 \mathrm{M}$ hydrazine-0.5 $\mathrm{M}$ glycine buffer, $\mathrm{pH} 9.5,0.001 \mathrm{M} \mathrm{MgCl}_{2}, 0.02 \mathrm{M}$ cysteine, $0.025 \mathrm{M} \mathrm{KF}, 0.006 \mathrm{M}$ ATP, $0.01 \mathrm{M}$ glycerol, $0.001 \mathrm{M} \mathrm{NAD}^{+}$and $10 \mu \mathrm{l}$ Baranowski enzyme. $\mathrm{O}$, Glycerol dehydrogenase; $0.033 \mathrm{M}$ sodium pyrophosphate, $0.17 \mathrm{M}$ glycerol, $0.001 \mathrm{MNAD}^{+}$ or NADP ${ }^{+} .0 .05 \mathrm{ml}$ bull sperm sonicate. Total volume $3 \mathrm{ml}$.

In this particular experiment, glycerokinase activity was measured under the conditions where $\mathrm{pH}$ was 9.5 instead of 7.4 used in other experiments, and dihydroxyacetonephosphate formed by the combined action of glycerokinase and crystalline $\mathrm{NAD}^{+}$-linked L-glycerol-3-phosphate dehydrogenase was caught up by hydrazine. The activity thus measured was much higher than that obtained with the routine method. The experiment was then repeated in order to observe glycerol dehydrogenase activity under the same experimental conditions as those for glycerokinase activity, i.e. with hydrazineglycine buffer, $\mathrm{pH} 9 \cdot 5$. There was no increase in the optical density at $340 \mathrm{~m} \mu$. Even if the reverse reactions, i.e. the oxidation of NADH or NADPH with glyceraldehyde or dihydroxyacetone as substrates, were followed, no decrease 
was observed in the optical density at $340 \mathrm{~m} \mu$ by the addition of either bull sperm sonicate or seminal plasma.

Effect of glycerol and $\mathrm{L}$-glycerol-3-phosphate on oxygen uptake and lactate formation

As reported by other investigators (White et al., 1954; Mann \& White, 1957; White, 1957), glycerol stimulated the oxygen uptake of washed bull

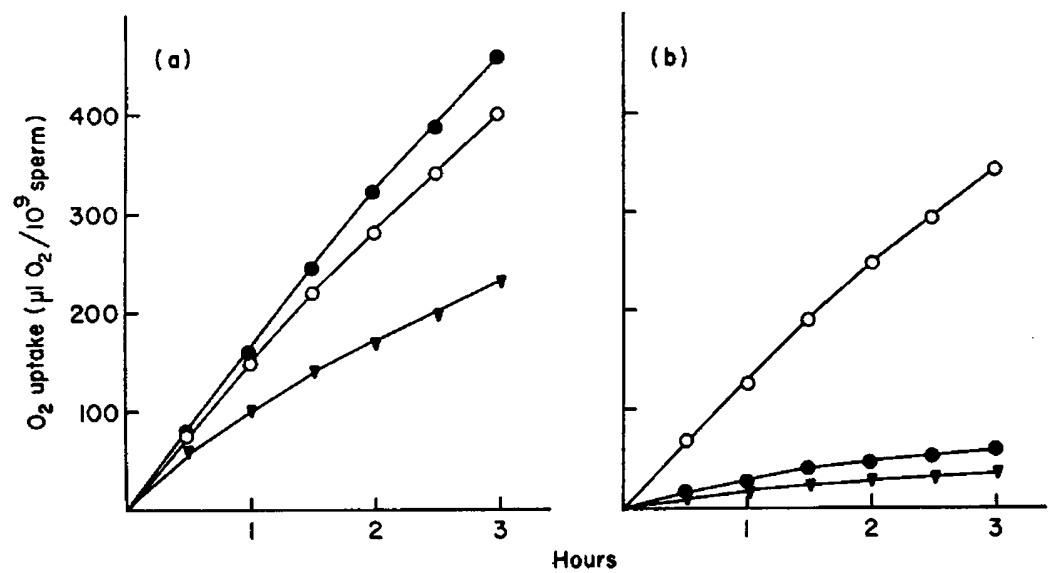

TExT-FIG. 5. Effect of glycerol and DL-glycerol-3-phosphate on oxygen uptake of washed bull and boar spermatozoa. (a) Bull, $8.5 \times 10^{8} / 2 \mathrm{ml}$; (b) boar, $4 \times 10^{8} / 2 \mathrm{ml}$. $\nabla$, No addition; 0 , DL-glycerol-3-phosphate $(0.02 \mathrm{M}) ; 0$, glycerol $(0.01 \mathrm{M})$.

TABLE 6

METABOLISM OF GLXGEROL AND DL-GLYGEROL-3-PHOSPHATE BY WASHED BULL AND BOAR SPERMATOZOA

\begin{tabular}{|c|c|c|c|c|c|}
\hline \multirow{2}{*}{ Animal } & \multirow{2}{*}{ Additions } & \multicolumn{4}{|c|}{ Increase or decrease $(\mu$ moles $/ 3 \mathrm{hr})$} \\
\hline & & Glycerol & $\begin{array}{l}\text { L-Glycerol- } \\
\text { 3-phosphate }\end{array}$ & Lactate & $\begin{array}{c}\text { Dihydroxy- } \\
\text { acetone- } \\
\text { phosphate }\end{array}$ \\
\hline Bull $\left(7 \times 10^{8}\right.$ sperm. $)$ & $\begin{array}{l}\text { Glycerol (20 } \\
\mu \text { moles) } \\
\text { DL-Glycerol-3- } \\
\text { phosphate } \\
(40 \mu \text { moles })\end{array}$ & $\begin{array}{l}-11.23 \\
+1.35\end{array}$ & $\begin{array}{l}+1 \cdot 47 \\
-9 \cdot 10\end{array}$ & $\begin{array}{l}+0.76 \\
+1.98\end{array}$ & $\begin{array}{l} \pm 0.00 \\
+0.20\end{array}$ \\
\hline Boar $\left(4 \times 10^{8}\right.$ sperm. $)$ & 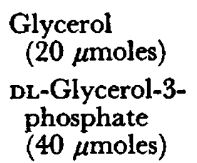 & $\begin{array}{r}-0.98 \\
+29.50\end{array}$ & $\begin{array}{l} \pm 0.00 \\
-18.91\end{array}$ & $\begin{array}{l}+0.05 \\
+0.19\end{array}$ & - \\
\hline
\end{tabular}

spermatozoa and led to the formation of lactic acid (Text-fig. 5a and Table 6). Since the present experiments were performed with a phosphate-poor medium, the amount of lactic acid formed was much less than that reported with a phosphate-rich medium, probably due to the fact that phosphate inhibits the lactate oxidation (cf. Mann \& White, 1957). The disappearance of added 
glycerol was also followed by an accumulation of L-glycerol-3-phosphate, suggesting the possibility that this compound is formed as an intermediate of glycerol utilization.

In Text-fig. 5 is also shown the effect of DL-glycerol-3-phosphate on the oxygen uptake of washed bull spermatozoa. The addition of DL-glycerol-3phosphate also caused an increased oxygen uptake, nearly up to the rate obtained with glycerol. In some cases the rate of oxygen uptake with DL-glycerol3-phosphate exceeded that with glycerol. At the same time a marked disappearance of added L-glycerol-3-phosphate was observed (Table 6). Living organisms utilize only L-glycerol-3-phosphate, but not its D-isomer, and this is also true of bull sperm mitochondria (Mohri et al., 1965). The disappearance of L-glycerol-3-phosphate was accompanied by an accumulation of lactic acid and a small amount of dihydroxyacetonephosphate, a logical intermediate of the metabolism of L-glycerol-3-phosphate. The observed formation of free glycerol from the added DL-glycerol-3-phosphate would be a result of the action of the phosphatase contained in the spermatozoa. In contrast to the high activity of phosphatase in the seminal plasma, however, neither washed bull spermatozoa nor any of their parts obtained after fractionation showed appreciable phosphatase activity, at least at neutral $\mathrm{pH}$.

Assuming that L-glycerol-3-phosphate is first oxidized to dihydroxyacetonephosphate by the mitochondrial oxidase system and then to $\mathrm{CO}_{2}+\mathrm{H}_{2} \mathrm{O}$ via lactic acid (more correctly via pyruvic acid) through the tricarboxylic acid cycle, the amount of glycerol or L-glycerol-3-phosphate removed during the incubation of sperm suspensions, corrected for the accumulation of intermediates, well accounts for the increment in the oxygen uptake of the sperm suspensions. In washed bull spermatozoa, the enhancement of oxygen uptake by glycerol or L-glycerol-3-phosphate did not lead to any remarkable change in sperm motility.

In Text-fig. 5(b) and Table 6 are also shown the results obtained with washed boar spermatozoa, where the activity of glycerokinase was found to be relatively low. The endogenous oxygen uptake of washed boar spermatozoa was much lower than that of washed bull spermatozoa, and the addition of glycerol did not improve markedly this low oxygen uptake. Analyses of glycerol and possible products before and after the incubation of sperm suspension also indicated that washed boar spermatozoa could not utilize the added glycerol effectively.

On the other hand, a considerable increase in the oxygen uptake was caused by adding DL-glycerol-3-phosphate, up to a rate almost comparable to that obtained with this compound in washed bull spermatozoa. Although most of the added L-glycerol-3-phosphate (about 50\% of DL-glycerol-3-phosphate) disappeared after $3 \mathrm{hr}$ incubation of the sperm suspension, there was an accumulation of free glycerol over the amount of L-glycerol-3-phosphate removed, probably due to the action of spermatozoan phosphatase. Half or more of the formed glycerol, however, would originate from D-glycerol-3-phosphate, which is not utilized directly by living organisms. Thus, at least the difference between the L-glycerol-3-phosphate removed and half of the free glycerol accumulated would be the amount of L-glycerol-3-phosphate directly utilized by washed boar spermatozoa. This amount is still quite sufficient to account 
for the observed increase in the oxygen uptake, if calculation is made according to the above-mentioned assumption.

Furthermore, in washed boar spermatozoa, the addition of DL-glycerol-3phosphate also brought about an improvement of motility, while this was not the case with free glycerol.

\section{Effect of fructose on glycerokinase activity}

It has been reported that in the presence of both fructose and glycerol a definite 'sparing effect' was exerted by glycerol on the rate of aerobic fructolysis in washed ram spermatozoa (Mann \& White, 1957). Since the first step of fructose utilization is either phosphorylation to fructose-6-phosphate by the action of hexokinase or a conversion to fructose-1-phosphate by the action of fructokinase, both of which require ATP, there is a possibility that the 'sparing effect' is a result of competition between hexokinase or fructokinase and glycerokinase for available ATP molecules.

As can be seen from Table 7, the glycerokinase activity of the mid-piece

TABLE 7

EFFECT OF FRUCTOSE ON GLYGEROKINASE ACTIVITY

\begin{tabular}{l|c|c}
\hline & Activity (unit/mg protein) \\
\cline { 2 - 3 } & -Fructose & + Fructose \\
\hline Bull & 1.83 & 1.22 \\
Sperm sonicate & 5.65 & 5.71 \\
Mid-piece fraction & & \\
\hline
\end{tabular}

fraction of bull spermatozoa, which contains little activity of the enzymes involved in fructolysis, was not affected by the presence or absence of fructose. In agreement with the above postulation, however, the formation of L-glycerol3-phosphate from glycerol in the sperm sonicate containing the whole fructolysis system was somewhat depressed in the presence of fructose.

\section{DISGUSSION}

The properties of glycerokinase obtained from bull spermatozoa, i.e. $\mathrm{pH}-$ activity curve, Michaelis constant, etc., are quite similar to those of rat liver glycerokinase reported by Bublitz \& Kennedy (1954). However, in contrast to glycerokinase from other animal sources, known to be a soluble enzyme, the spermatozoan glycerokinase appears to be firmly bound to mitochondria, since it is resistant to the usual extraction procedures. This characteristic may have some relation to the dehydration process which takes place during spermiogenesis, or to the limited space in mature spermatozoa. In this respect, it is interesting that glycerokinase found in peanut seedlings has been also reported to be bound to mitochondria (Stumpf, 1955). It is likely that glycerokinases from other sources are loosely bound to mitochondria and thus easily obtain- 
able in a soluble form, because the reaction catalysed by glycerokinase is one of the initial steps in fat synthesis, which proceeds in mitochondria.

The finding of glycerokinase in bull and ram spermatozoa also threw light on the hitherto unexplained mechanism of the transformation of glycerol in these spermatozoa. From the facts that glycerol increases the oxygen uptake of washed bull and ram spermatozoa, resulting in an accumulation of lactic acid, Mann \& White (1957) and White (1957) postulated the conversion of glycerol to dihydroxyacetone as the initial step of glycerol utilization, followed by a glycolytic breakdown to lactic acid via dihydroxyacetonephosphate. As the present experiments failed to detect the activity of glycerol dehydrogenases, both $\mathrm{NAD}^{+}$- and $\mathrm{NADP}^{+}$-linked, which are indispensable for the oxidation of glycerol to dihydroxyacetone, the above process would not be the main pathway for glycerol utilization. The fact that dihydroxyacetone gives rise to an increased oxygen uptake, and also to the formation of lactic acid to the extent obtained with glycerol (Mann \& White, 1957; White, 1957), could be explained by the present result that this compound is readily phosphorylated to dihydroxyacetonephosphate by the spermatozoan glycerokinase, although at a somewhat slower rate than the phosphorylation of glycerol.

The following evidence, on the other hand, favours the view that glycerol is first phosphorylated to L-glycerol-3-phosphate, which, in turn, is oxidized to dihydroxyacetonephosphate and then enters into the glycolytic system. (1) Bull and ram spermatozoa possess glycerokinase of relatively high activity. (2) L-Glycerol-3-phosphate added to washed full spermatozoa was oxidized as readily as glycerol and also produced lactic acid. (3) L-Glycerol-3-phosphate accumulated after the aerobic incubation of sperm suspensions with glycerol. (4) Dihydroxyacetonephosphate was detected after the aerobic incubation of sperm suspensions with DL-glycerol-3-phosphate, although in a small amount. (5) The process of glycerol utilization depends strictly on the presence of oxygen (Mann \& White, 1957). This coincides with the fact that L-glycerol-3-phosphate is stoichiometrically oxidized to dihydroxyacetonephosphate by mitochondrial L-glycerol-3-phosphate dehydrogenase in bull spermatozoa (Mohri et al., 1965). Soluble NAD ${ }^{+}$-linked L-glycerol-3-phosphate dehydrogenase is lacking in these spermatozoa. Under anaerobic conditions, the glycerol utilization would stop at this stage, giving rise to no accumulation of lactic acid. (6) Although some free glycerol was formed after the incubation of washed bull spermatozoa with DL-glycerol-3-phosphate (cf. also Mann \& White, 1957), the amount of L-glycerol-3-phosphate utilized after subtracting the amount of accumulated glycerol and other intermediates was quite enough to account for the increase actually observed in oxygen uptake, as shown even in an extreme case of washed boar spermatozoa. (7) In washed boar spermatozoa, which show a relatively low activity of glycerokinase, only L-glycerol-3-phosphate was actively metabolized, causing the increased oxygen uptake. Free glycerol, on the other hand, exerted no appreciable effects. In sea-urchin spermatozoa, which have L-glycerol-3-phosphate dehydrogenase bound to a particulate component (Mohri, 1957), but not glycerokinase, glycerol also failed to increase their oxygen uptake.

It has been reported that both $\alpha$ - and $\beta$-phosphoglycerol were effective in 
producing an increase in oxygen uptake of washed ram spermatozoa (Mann \& White, 1957). These results appear somewhat in conflict with the above idea, because $\beta$-phosphoglycerol (glycerol-2-phosphate) is not oxidized by the mitochondrial oxidase system. There are two possibilities, however, which would explain such results. One possibility is that the sample of glycerol-2phosphate used was contaminated with L-glycerol-3-phosphate. In fact, in a previous experiment using the mid-pieces isolated from bull spermatozoa, a commercially available sample of glycerol-2-phosphate was oxidized at exactly the same rate as L-glycerol-3-phosphate, and enzymatic analysis revealed that this product contained a certain amount of L-glycerol-3-phosphate (Mohri et al., 1965). Another possibility is that glycerol-2-phosphate was converted into L-glycerol-3-phosphate via free glycerol, owing to the combined action of spermatozoan phosphatase and glycerokinase, and then oxidized by the mitochondrial oxidase system. On the other hand, White (1957) reported that phosphoglycerol neither produced any increase in the oxygen uptake nor formed appreciable lactic acid in washed bull spermatozoa. Although there is no further description of the phosphoglycerol used in his experiments, the compound should be glycerol-2-phosphate. Since phosphatase activity of bull spermatozoa was found to be quite low, there would be less possibility that glycerol once formed from glycerol-2-phosphate is again phosphorylated to L-glycerol-3-phosphate.

The accumulation of fructose during the course of aerobic glycerol metabolism reported in washed bull spermatozoa (White, 1957) can be explained consistently with the present view of glycerol metabolism. It has been reported that the addition of fructose resulted in less glycerol- $1-{ }^{14} \mathrm{C}$ utilization by twicewashed bull spermatozoa (O'Dell, Almquist \& Flipse, 1959) and, conversely, that glycerol exerted a 'sparing effect' on fructolysis in washed bull spermatozoa (White, 1957). These phenomena could be understood as the result of competition for ATP between glycerokinase and hexokinase or fructokinase, both of which catalyse the initial reaction in glycerol and fructose utilization, respectively.

A question then arises as to why these spermatozoa contain glycerokinase, because glycerol as such is not present in semen except perhaps in traces. A most likely source of free glycerol would be diglycerides, which are suggested by Terner \& Korsh (1962) to be an adequate substrate to support endogenous respiration of bull spermatozoa by the oxidation of the fatty acids. Phospholipids would be another possible source of glycerol. According to Hartree \& Mann (1960), however, choline-plasmalogen, the main phospholipid of bull and ram spermatozoa, is hydrolysed only to the stage of lysoplasmalogen by phospholipase A. Even if glycerophosphorylesters were formed from lysophospholipids, no diesterase to hydrolyse glycerophosphorylesters has so far been detected in sperm cells, in spite of the fact that high concentrations of glycerophosphorylcholine are found in seminal plasma of many species. In this connection, it is interesting that a diesterase is found in the female genital tract of many animals (White, Wallace \& Stone, 1963). The liberated L-glycerol-3-phosphate from glycerophosphorylcholine could be directly oxidized and utilized as an energy source by the spermatozoa in the female genital tract. 
An entirely different possibility also exists concerning the formation of free glycerol (Hers, 1957). Namely, fructose, another main constituent of seminal plasma, is first phosphorylated to fructose-1-phosphate with the aid of fructokinase, and then split into glyceraldehyde and dihydroxyacetonephosphate by aldolase. Glyceraldehyde thus formed would be then converted into glycerol by either NADP ${ }^{+}$-linked glycerol dehydrogenase (aldose-reductase) or NAD ${ }^{+}$linked alcohol dehydrogenase. The existence of such a pathway in spermatozoa, however, can be excluded by the fact that no oxidation of NADH or NADPH occurred in bull sperm sonicate or seminal plasma with glyceraldehyde as substrate, although the presence of aldose-reductase in ram seminal vesicle has been reported (Hers, 1957).

In summarizing the above facts, the following pathway can be drawn concerning the metabolism of glycerol and related compounds in bull (and possibly also ram, goat and cock) spermatozoa.

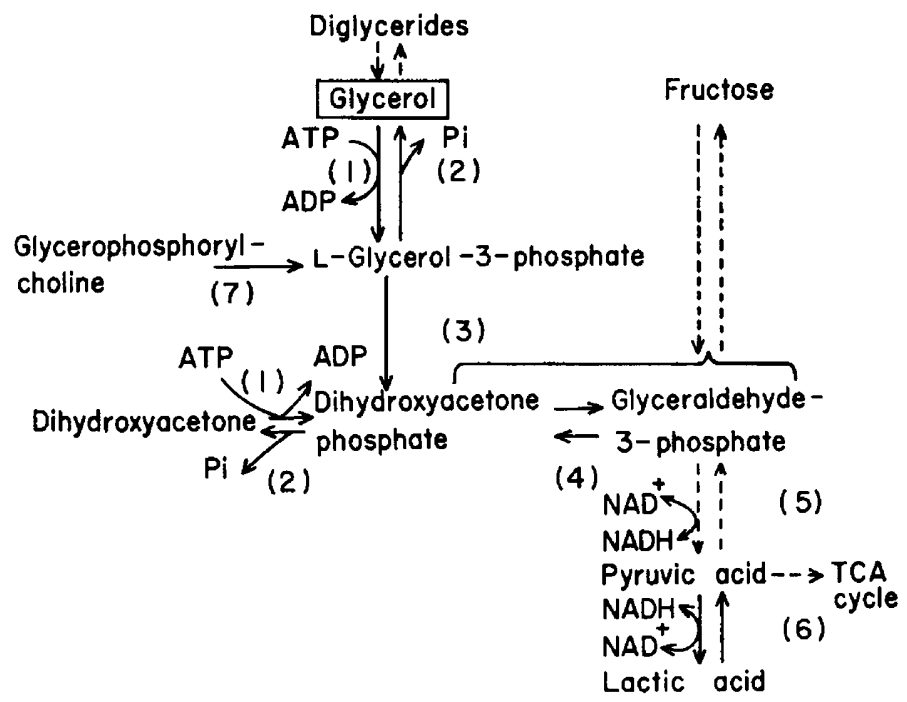

(1) Glycerokinase.

(2) Phosphatase (seminal or spermatozoan).

(3) Mitochondrial L-glycerol-3-phosphate dehydrogenase.

(4) Triosephosphate isomerase.

(5) Glyceraldhyde-3-phosphate dehydrogenase.

(6) Lactic dehydrogenase.

(7) Uterine diesterase.

Finally, the present results raise another question as to whether phosphorylation of glycerol is an essential step in the transfer of glycerol into sperm cells across the membrane. It has been shown empirically that the deep freeze preservation of boar spermatozoa (possessing weak glycerokinase activity and utilizing only L-glycerol-3-phosphate) in the presence of glycerol is not so successful as that of bull spermatozoa (possessing high glycerokinase activity and utilizing both glycerol and L-glycerol-3-phosphate).

The uptake of glycerol into boar spermatozoa, which is necessary to protect the sperm cells from the adverse effects of freezing, might not occur so efficiently. 
More damage might thus be caused than with bull spermatozoa. This interpretation must await further elucidation.

\section{ACKNOWLEDGMENTS}

The starting point of this work was carried out at the Wenner-Gren Institute, Stockholm, Sweden, while one of us (H.M.) was a recipient of a fellowship from the Lalor Foundation. It is a pleasure to thank Dr L. Ernster of the Wenner-Gren Institute for his valuable suggestions.

The authors are indebted to the director and staff of the Misaki Marine Biological Station, University of Tokyo, for supplying sea-urchin and starfish materials, to the director and staff of the Irikawa Hatchery for supplying rainbow trout semen, and to Dr R. Iizuka of the Department of Obstetrics and Gynecology, School of Medicine, Keio University, for supplying human semen. Thanks are also due to our colleagues in the National Institute of Animal Industry for their generous supply of semen samples. Finally we are grateful to Dr J. C. Dan of Ochanomizu University for reading through the manuscript.

This work was supported by a Grant-in-Aid for Fundamental Scientific Research from the Ministry of Education.

\section{REFERENCES}

Bublitz, C. \& Kennedy, E. P. (1954) Synthesis of phosphatides in isolated mitochondria. III. The enzymatic phosphorylation of glycerol. F. biol. Chem. 221, 951.

Bücher, T. \& HOHORST, H.-J. (1963) Dihydroxyacetone phosphate, fructose-1,6-diphosphate and D-glyceraldehyde-3-phosphate. Determination with glycerol-1-phosphate dehydrogenase, aldolase and triosephosphate isomerase. In: Methods of Enzymatic Analysis, p. 246. Ed. H. U. Bergmeyer. Academic Press, New York.

Burton, R. M. (1955) Glycerol dehydrogenase from Aerobacter aerogenes. In: Methods in Enzymology, Vol. 1, p. 397. Ed. S. P. Colowick and N. O. Kaplan. Academic Press, New York.

Chrso, H. (1960) Enzymatic pathways in the formation of sorbitol and glycerol in the diapausing egg of the silkworm, Bombyx mori. I. On the polyol dehydrogenases. F. Insect Physiol. 5, 1.

Faulkner, P. (1958) Polyol dehydrogenase of the silk-worm. Biochem. 7. 68, 374.

Fiske, C. H. \& Subbarow, Y. (1925) The colorimetric determination of phosphorus. 7. biol. Chem. 66, 375 ,

Hartree, E. F. \& MANn, T. (1960) Crystalline lysoplasmalogen (lysophosphatidal choline): preparation from heart muscle and action on erythrocytes and spermatozoa. Biochem 7. 75, 251.

Hers, H. G. (1957) Le métabolisme du fructose. Editions Arscia, Bruxelles.

HоноRsт, H.-J. (1963a) L-(-)-Glycerol-1-phosphate determination with glycerol-1-phosphate dehydrogenase. In: Methods of Enzymatic Analysis, p. 215. Ed. H. U. Bergmeyer. Academic Press, New York.

Hоновsт, H.-J. (1963b) L-(+)-Lactate determination with lactic dehydrogenase and DPN. In: Methods of Enzymatic Analysis, p. 266. Ed. H. U. Bergmeyer. Academic Press, New York.

Kanatani, H. (1964) Spawning of starfish: action of gamete-shedding substance obtained from radial nerves. Science, N.Y. 146, 1177.

MANN, T. (1946) Studies on the metabolism of semen. 3. Fructose as a normal constituent of seminal plasma. Site of formation and function of fructose in semen. Biochem. $7.40,481$.

MANN, T. \& White, I. G. (1957) Glycerol metabolism by spermatozoa. Biochem. 7. 65, 634.

MOHRI, H. (1957) Effect of malonate on oxygen uptake and dehydrogenase activity in sea-urchin spermatozoa. 7. Fac. Sci. Tokyo Univ., IV, 8, 65.

Mohri, H., Mohri, T. \& ERnster, L. (1965) Isolation and enzymic properties of the midpiece of bull spermatozoa. Expl Cell Res. 38, 217.

O'Dell, W. T., Almquist, J. O. \& Flipse, R. J. (1959) Metabolism of bovine semen. VI. Effect of fructose and arabinose on the uptake and metabolic utilization of glycerol-1- $\mathrm{C}^{14}$ by bovine spermatozoa. 7. Dairy Sci. 42, 89. 
O'Dell, W. T., Futpse, R. J. \& Almquist, J. O. (1956) Metabolism of bovine semen. III. Uptake and metabolic utilization of glycerol-1-(- ${ }^{14}$ by bovine spermatozoa. F. Dairy Sci. 39, 214.

RYLEY, J. F. (1955) Studies on the metabolism of the protozoa. 4. Metabolism of the parasitic flagellate Strigomonas oncopelti. Biochem. 7. 59, 353.

Stumpr, P. K. (1955) Fat metabolism in higher plants. III. Enzymic oxidation of glycerol. Pl. Physiol., Lancaster, 30, 55.

TERNER, G. \& Korsh, G. (1962) The biosynthesis of $\mathrm{C}^{14}$-labeled lipids by isolated bull spermatozoa. Biochemistry, 1, 367.

WHITE, I. G. (1957) Metabolism of glycerol and similar compounds by bull spermatozoa. Am. $\mathcal{F}$. Physiol. 189, 307.

White, I. G. (1959) Studies on the estimation of glycerol, fructose and lactic acid with particular reference to semen. Aust. F. exp. Biol. med. Sci. 37, 441 .

Whrte, I. G., Blackshaw, A. W. \& Emmens, C. W. (1954) Metabolic and motility studies relating to the low temperature storage of ram and bull spermatozoa. Aust. vet. 7. 30, 85.

White, I. G., Wallace, J. C. \& Stone, G. M. (1963) Studies on the glycerophosphorylcholine diesterase activity of the female genital tract in the ewe, cow, sow and rat. J. Reprod. Fert. 5, 298.

Wieland, O. (1963) Glycerol. In: Methods of Enzymatic Analysis, p. 211. Ed. H. U. Bergmeyer. Academic Press, New York. 